\title{
The analysis of the proportion of Chinese national health expenditure in GDP
}

\author{
Jing Xiao \\ Maple Leaf International School, Dalian 116650, China \\ 1749946247@qq.com
}

\begin{abstract}
With the development of national economic and people's health consciousness, the national health expenditure has increased the attention of government and researchers. Based on the introduction of the national health expenditure and accounts, this paper analyzed the development of Chinese national health expenditure. And the factors influence the proportion of Chinese national health expenditure in GDP were emphatically analyzed which can help government to reform the medical and health system in China.
\end{abstract}

Keywords: National health expenditure; GDP; Health services.

\section{Introduction}

The national health expenditure generally refers to the total funds a country spends on medical and health services in a certain period of time (usually one year). The national health expenditure can reflect the whole operation process of the funds of medical and health services, and can analyze and evaluation the raising and distribution of the medical and health services founds. In recent years, with the speeding up of aging population, the rapid growth of economic and the transformation of the disease patterns, the demands of the medical and health resources increase rapidly which leads to the rapid growth of countries' national health expenditure. Researches and governments began to pay attention to the development of the national health expenditure. The proportion of national health expenditure in GDP usually been used to evaluate the adaptation of a country's development of medical and health services and economic growth [1]. Generally, if the country's economic development level is higher, the proportion of national health expenditure in GDP will also be increased [2]. The accurate prediction of the development of the proportion of national health expenditure in GDP is very important to the formulation of health care policy, the equitable distribution and effective use of health resources.

\section{The national health expenditure and accounts}

The national health expenditure is one country's total health founds consumption of the whole society in a certain period of time (usually one year). The national health account is the extension of the national economic accounting in health field, the national health expenditure can be called the GDP of health, is the macro-economic indicators to evaluate the development of a country's health services. The results of the total health accounting can be applied to the evaluation of policy formulation and implementation in many aspects, like the health financing, the allocation of health resources, the using of health capital, and the covers of medical security system. The national health account is one of the basic research relates to health policy, and also the general indicator of the international comparison of health services development. Because of the significance of national health expenditure, WHO and countries around the world attach great importance to the national health accounts.

The national health accounting framework internationally applied is based on the "national ledger accounts" write by the OECD, derives from the "system of health accounting 1.0" published in 2000 and the "system of health accounting 2011" modified according to the latest development of international health services. The account of the national health can be used in the health policy analysis which is the main part of the national health accounts work. For the better application of the 
results of national health accounts, there are different kinds of indicators of evaluation of health expenditure put forward by WHO and countries in the world. The accuracy evaluation of the indicators will directly affect the formulation and adjustment of health policy.

\section{The development of Chinese national health expenditure}

The change of the proportion of Chinese national health expenditure can properly reflect the history of health expenditure process. From 1978 to 2012, the national health expenditure in China has showed a trend of sustained growth, increased from 11.02 billion yuan to 2.78 trillion yuan. The 1990 's is the turning point of Chinese health services, before 1990's, the proportion of Chinese national health expenditure in GDP is between 3\%-3.6\%; while after 1990's, the proportion began to increase. However, the proportion began to decrease in 1992, after four years' trough, it rebound to $4.36 \%$ in 1998. In 2012, the proportion increased to 5.36\%. Therefore, it can be summarized that the change of the proportion of Chinese total health expenses in GDP performs a circuitous rising trend.

The national health expenditure in China is consisted by three parts: the individual health expenditure, the social health expenditure and the government fiscal health expenditure. In 2000, the government fiscal health expenditure accounts for $15.47 \%$ of the total health expenses, the social health expenditure accounts for $25.55 \%$ of the total health expenses, the individual health expenditure accounts for $58.98 \%$ of the total health expenses; while in 2012, the government fiscal health expenditure accounts for $30.04 \%$ of the total health expenses, the social health expenditure accounts for $35.61 \%$ of the total health expenses, the individual health expenditure accounts for $34.35 \%$ of the total health expenses[3]. According to the constitution of the national health expenditure, the government fiscal and social health expenditure are in a growing state, but the total health expenditure is at a lower level, and the proportion of individual health expenditure is higher which is the disadvantages of healthcare system in China. In China, compared with the development of other social services, the health services development is far behind others, the saving of the health care cost isn't promoting the development of economy but leads to the contradiction between the incomplete of health service system and the inhabitants' increasing health demand is increasingly prominent, and the complete of the health service system needs mutual coordination and cooperative work of each department.

\section{The factors influence the proportion of Chinese national health expenditure in GDP}

Because of the change of policies and the unpredictable of the health service cost, the factors influence the proportion of Chinese national health expenditure in GDP not only contains internal factors but also contains many externa factors which have strong uncertainty. The influencing factors can be summarized into four aspects: the macro-economic, the financing structure, the aging of population and the urbanization rate and the number of doctors.

\subsection{The influence of macro-economic}

The level of a countries' health expenditure is closely associate with the level of economic development. With the development of economic, the demands of health service will accordingly increase which is the main reason of the increase of national health expenditure. Generally, in the developed countries and areas, the national health expenditure is high and growing rapidly. In China, GDP as the most important factor to measure the level of macro-economic development is the determinant of national health expenditure increase. The Chinese national health expenditure has maintained the same change trend of the GDP in China, has increased with the growth of GDP, but the growth rate is different. As to the proportion of Chinese national health expenditure in GDP, the change of the proportion is not always growing, there have been up and down during those years but the overall trend is increasing. With the improvement of residents' living standard, people's health consciousness become more and more strong. 


\subsection{The influence of financing structure}

From the perspective of the financing source, the national health expenditure in China can be divided into three parts: the individual health expenditure, the social health expenditure and the government fiscal health expenditure[4]. The government fiscal expenditure on health refers to the total number of funding spending on the development of health service, its main parts are free medical care expenses and public funds for health services. The medical and health service has very strong commonality, government should play the leading role in the development of medical and health services in both panned economy and market economy. The proportion of the government health expenditure in total health expenditure of a country usually used to measure the important level of medical and health services to the government.

After the reform and openness in China, because of the lack of government financial resources, the resources oriented health policy gradually transformed into economic oriented health policy. The health service reform is mainly relying on the release of some national policies and allow some market-oriented measures to make up the inadequacy of health investment. Although the economic oriented health policy objectively eased the burden of the government in the short term, but it also brings some disadvantages such as the unreasonable rising of medical expenses. The proportion of the government health expend in Chinese national health expenditure is decreasing before 2000 and comes to the lowest in 2000. While after the year 2000, the proportion keeps increasing which means the government began to intensify the investment in health care.

\subsection{The influence of population aging}

The problem of population aging has been paly an indispensable role in the study of the growth of the total health expenses[5]. In order to control the population growth, China began to carry the family planning policy in the late $20^{\text {th }}$ century which caused the greatly drop of birth rate and accelerated population aging. The countries firstly emerging the population aging problem are mostly developed countries with good national economic development, the good economic development is the foundation for those countries to solve the ageing problem. However, China is still a developing country while the population aging problem emerges, the economic power of China is not strong enough which will increase the difficult to solve the aging problem. Because of the increasing of old people, the number of patients will increase and the medical demand will also be increased. The elderly people's medical expenses are much more than the young people.

Since the year 1978, the Chinese national health expenditure has been increased rapidly, and the proportion in GDP also increased. According to the data of the proportion of Chinese national health expenditure in GDP and the proportion of people older than 65, the proportion of the health expenditure is increasing with the increase of the population of old people. Therefore, the population aging problem is one of those factors influence the proportion of Chinese national health expenditure in GDP.

\subsection{The influence of urbanization rate and number of doctors}

Since the 20th century, urbanization has become a hot trend all over the world. The concept of urbanization contains two aspects: the internal and the external. The internal form of urbanization is the improvement of personnel quality and the adjustment of urban social structure; the external form of urbanization is the growing urban population and the continuous expansion of the city size. In 1978, the proportion of urban population of China is $17.92 \%$, while in 2012 , the proportion increases to $52.57 \%$. The rapid speed of urbanization will cause the increase of national health expenditure. On one hand, the environmental pollution accompanied by the urbanization could seriously threaten the public health, and also directly impact the public health costs; on the other hand, the process of urbanization also represents the improvement of national quality, and increasing of the demands for medical and health resources. Therefore, the medical and health services began to flourish and the health practitioners also increased significantly in recent years. The increase of health practitioners would make the social health care services become more complete, but there also exist the phenomenon of the excessive consumption of medical services induced by doctors or hospitals. The 
proportion of Chinese national health expenditure in GDP can be influenced by the level of urbanization and the number of doctors.

\section{Conclusion}

With the development of people's health consciousness, the government has increased the focus on the medical and health services; the investment to the health service has become more and more significant. However, the development of China's health service also has many problems: firstly, the health resources are insufficient and the allocation of resources is unreasonable, the health service development lags far behind the national economic development. Secondly, the medical security system and management system have not been properly developed, the drug product price is unreasonable, the production circulation is out of order and social capital is difficult to access. What's more, in the medical and health area, the relevant policies, laws and regulations is not sound which make it difficult to the effective regulation of health service. Therefore, the government is dedicated to medical and health system reform which is very important to the health service development. Let it become the breakthrough of the transformation of the economic growth mode and the improvement of the economic system in the new period. The analysis of the influence factors of national health expenditure can help to understand the development of the medical and health system in China and help government to reform the system in order to enhance the health level of residents.

\section{References}

[1] Glassman, A., U. Giedion, and K. Mcqueston, Priority setting for health in emerging markets. Journal of Comparative Effectiveness Research, 2015. 2(2): p. 283-91.

[2] .Blanco, M.Á., G.R. Urbanos, and I.J. Thuissard Vasallo, [Real per capita health spending by age and sex in Spain (1998-2008): changes and effects on public healthcare expenditure projections]. Gaceta Sanitaria, 2012. 27(3): p. 220-225.

[3] .Zhang yuhui, et al., The result and analysis of China's national health expenditure in 2012. Chinese Health Economics, 2012. 31(04): p. 5-11.

[4] .Yin aitian, Wang lihua, and Qian dongfu, Comparative research on total expenditure on hleath and its composition between China and other countries. Chinese Health Economics, 2005. 24(08): p. 5-8.

[5] .Han, K., M. Cho, and K. Chun, Determinants of Health Care Expenditures and the Contribution of Associated Factors: 16 Cities and Provinces in Korea, 2003-2010. Journal of preventive medicine and public health = Yebang? ihakhoe chi, 2013. 46(6): p. 300-8. 